American Journal of Biotechnology and Biochemistry 3 (3): 141-144, 2007

ISSN 1553-3468

(C) 2007 Science Publications

\title{
Tribochemical Performance of Cell-treated Nickel Matrix
}

\author{
${ }^{1}$ Bing Shi, ${ }^{1}$ Thomas B. Kuhn, ${ }^{2}$ Hong Liang and ${ }^{1}$ Lawrence K. Duffy \\ ${ }^{1}$ Department of Chemistry and Biochemistry, University of Alaska Fairbanks, Fairbanks, AK USA \\ ${ }^{2}$ Department of Mechanical Engineering, Texas A\&M University, College Station, TX USA
}

\begin{abstract}
Nickel (Ni) has been studied as a biomaterial for a long time because of the unique mechanical properties and corrosion resistance. In this study, the frictional properties and wettability of $\mathrm{Ni}$ under dry and lubricated conditions, including cell treatment, were compared in order to investigate its tribological performance under conditions similar to that in a human body. The wettability was evaluated and the morphology and the microstructure of Ni samples were investigated. Cells were cultured on a $\mathrm{Ni}$ matrix and observed using an inverted optical and fluorescence microscope. Dry friction tests were conducted and compared Ni lubricated with the bovine serum albumin (BSA) solution or the cell culture media. The lubrication behavior and biofluid mechanisms are discussed.
\end{abstract}

Key Words: Nickel, Ni, 3T3 cells, tribology

\section{INTRODUCTION}

The materials that have been used to study artificial joint performance include ceramics, polymers, stainless steel, and alloys such as CoNiCrMo, TiAlv ${ }^{[1-}$

${ }^{5]}$. Nickel-based alloys have been studied and used as biomaterials because they are corrosion resistant and have excellent metallurgical compatibility with alloying elements. Because of their mechanical strength and biocompatibility, metals, such as $\mathrm{Ni}$, are superior in load-bearing implants. Ni-alloys have been previously tested in medical applications such as cardiovascular ${ }^{[6,7]}$ gastroenterologic $^{[8]}, \quad$ urology $^{[9]}, \quad$ orthopedic $^{[10,11]}$ implants. The toxicity to cells and the tribological properties of Ni-based materials has not been studied in detail.

\section{MATERIALS AND METHODS}

The Ni sheets used in this research were designed as filters. The thickness of the Ni sheet was 4 $\mathrm{mm}$. Microscopically, Ni has an open pore structure. A pentagonal three-dimensional lattice of $\mathrm{Ni}$ can be seen under the microscope, and this lattice is the primary micro-shape of the Ni. The Ni sheets have macro-pores varying from $0.1 \mathrm{~mm}$ to $0.5 \mathrm{~mm}$. The scanning electron microscope (SEM) image showed that there are many micro cracks on the surface (Fig. 1).

The cells used in this study were Swiss 3T3 fibroblasts from ATCC. The Ni samples were sterilized by $70 \%$ alcohol solution and then exposed under UV light on both sides for 20 minutes. The culture media was Dulbecco's Modified Eagle Medium (DMEM, GIBCO), Fetal Bovine Serum (FBS) and penicillinstreptomycin (GIBCO) solution. Cells were cultured on $\mathrm{Ni}$ sheets and the cell densities for cell culture used for plating were between 100,000 cell $\mathrm{mL}^{-1}$ and 200,000 cell $\mathrm{mL}^{-1}$. The cells were grown for $48 \mathrm{hrs}$ after plating and then observed using an inverted phase-fluorescence microscopy ${ }^{[12]}$.

The wettability of the $\mathrm{Ni}$ sample was investigated using contact angle goniometer. Friction tests were conducted using the pin-on-disk mode of a Universal Micro-Tribotester (UMT, CETR). Reciprocating friction tests were performed using a rectangular aluminum holder which was fabricated in order to conduct the lubricated friction tests. The aluminum pin was $6.35 \mathrm{~mm}$ in diameter and the test materials were held inside the holder by two aluminum bars that are attached to the bottom of the holder. The normal load was $5 \mathrm{mN}$ and the velocity of the slider was $10 \mathrm{~mm} \mathrm{sec}{ }^{-1}$. The tests lasted $10 \mathrm{~min}$ and each individual test performed three times. The lubricant used was 1\% Bovine Serum Albumin (BSA) solution in $0.15 \mathrm{M} \mathrm{NaCl}$. Friction tests for 3T3 fibroblast treated Ni samples were performed after the cells were cultured for 48 hrs.

\section{RESULTS AND DISCUSSION}

After $48 \mathrm{hrs}$ of grown on $\mathrm{Ni}$, cells seldom attach to the matrix. A phase contrast microscope was

Corresponding Author: $\quad$ Lawrence K. Duffy, Department of Chemistry and Biochemistry University of Alaska Fairbanks PO Box 756160 Fairbanks, AK 99775-6160 USA 
used to observe the cells, but since Ni is not transparent, only the edge area could be observed. Only clumps with minimal anchoring were visible. Under the fluorescence microscope, $\mathrm{Ni}$ showed a weak fluorescence signal (Fig. 2). Since cells did not migrate up onto the sheet, almost no cells were observed to attach to the $\mathrm{Ni}$ matrix. For the few cells that did migrate, they clumped together instead of attaching to the surface of the Ni. This apparently toxic effect of the Ni substrate agrees with clinical reports of dermatitis ${ }^{[13]}$. Metallic nickel combines with carbonyl groups and leukocytosis has been reported ${ }^{[13,14]}$.
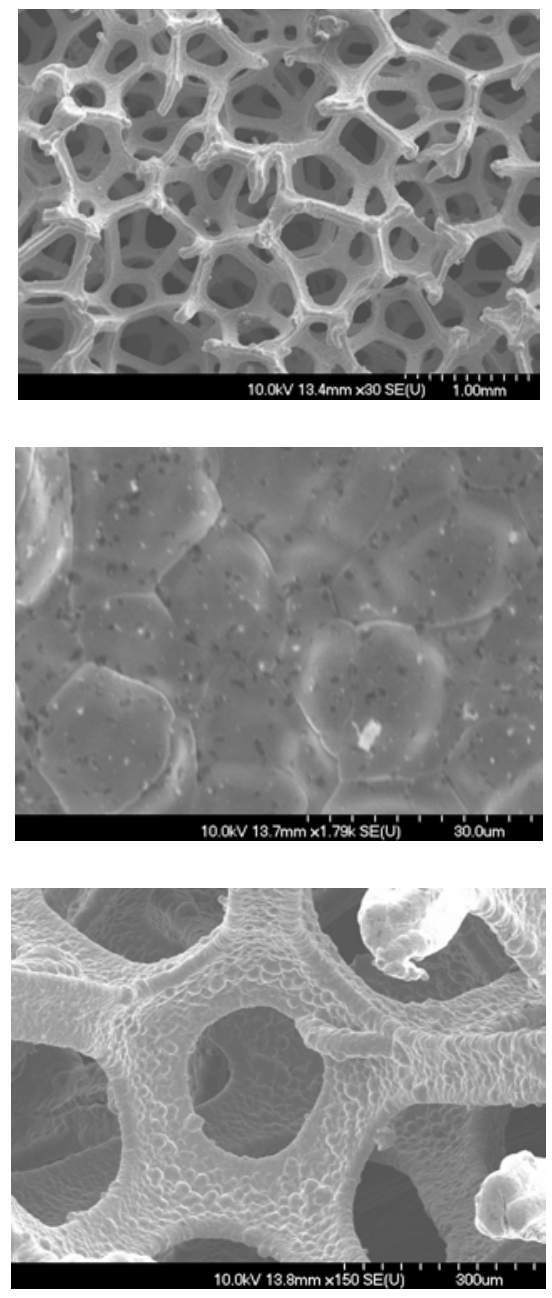

Fig. 1: Surface and microstructure of Ni.SEM images: left, overview; middle, pentagon; right, pore

The tribological character of $\mathrm{Ni}$ samples were characterized using the coefficient of friction and wettability. The dry friction tests had the highest average friction coefficient (0.6114) and the cell culture friction tests had the lowest average friction coefficient (0.3376) (Fig. 3). The coefficient of dry friction was smaller at the beginning of the test and increased. The $\mathrm{Ni}$ samples had lower friction coefficients at the beginning because Ni samples were soft and when the load was applied, substantial plastic deformation occurred which lowered the resistance. The lubricated $\mathrm{Ni}$ friction tests had the same trend in the tests but the change was smaller than that of the dry friction tests. The cell culture friction tests of $\mathrm{Ni}$ were the most constant, having the smallest friction coefficient.
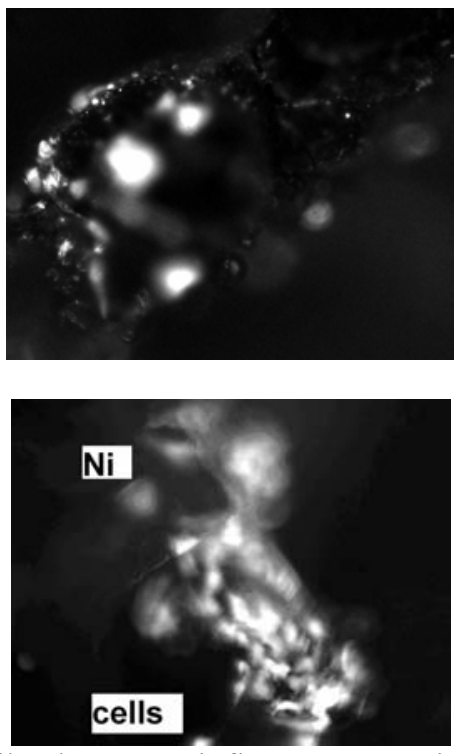

Fig. 2: Cell culture on $\mathrm{Ni}$, fluorescence microscope (20x) Top : Ni is fluorescence sensitive ; Bottom : Cells were forming clumps with minimal anchoring

The test areas on the Ni sample were deformed (lower than the original surface), and adhesive wear also occurred. Mutual transfer of materials could also be observed, which included the transfer of the particulate material from one surface to another, particle growth by further repetitive transfer, and finally as loose debris. The grooves can be seen along the sliding direction (Fig. 4). Because of the groove and debris, the friction coefficient increased with time. When the BSA lubrication solution was dropped on the surface, the lubricant solution gathered and formed a hemisphere. As the test continued, the hemisphere fluid started to extend, becoming flatter, suggesting the infiltration of the fluid into the porous structure.

For the cell culture friction tests, the culture media had a more protective effect than the BSA solution. During the lubricated friction tests, the 
lubricant was added before the tests. The short reaction time limited reactions on the lubricant film before the friction tests. In the cell culture friction tests, the cell culture procedure changed the wettability of the matrix

(a)

(b)

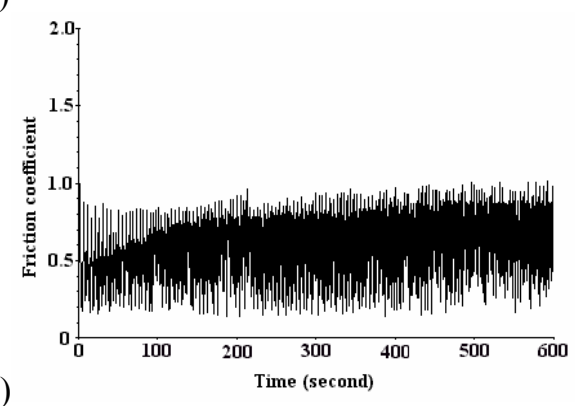

(c)
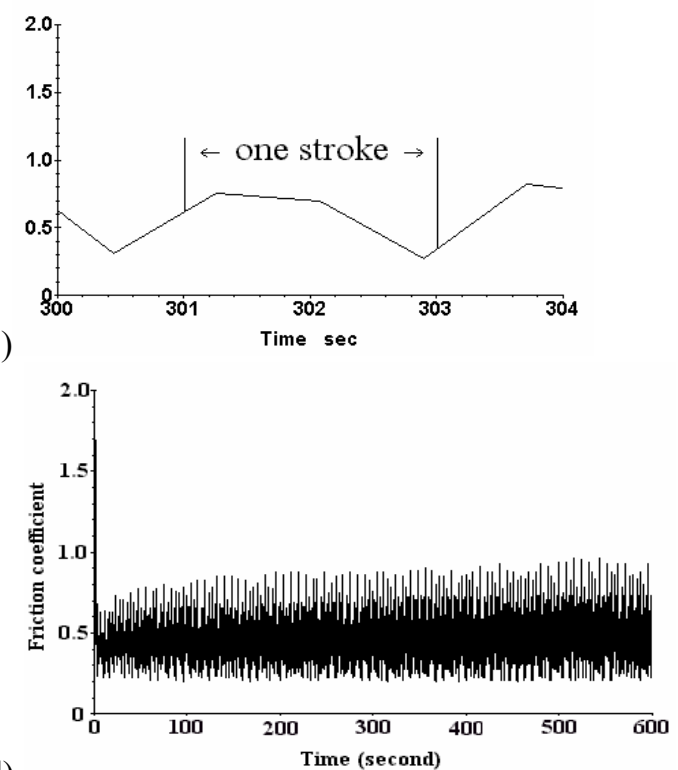

(d)

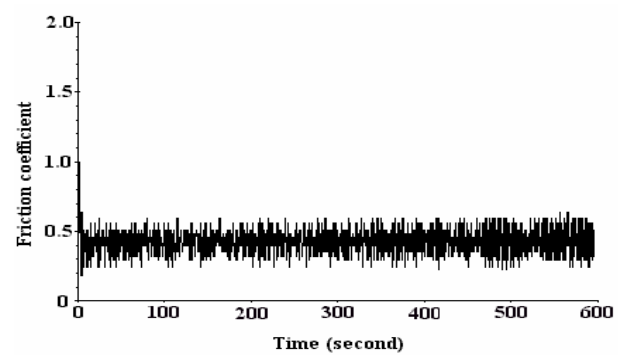

Fig. 3: Comparison of coefficients of friction of different type of tests of $\mathrm{Ni}$

a: dry friction test (Fcoe 0.61, MSE 0.28), b: single stroke, c: lubricated friction test (Fcoe 0.47, MSE 0.24), d: cell culture-treated samples friction test (Fcoe 0.34, MSE 0.14)
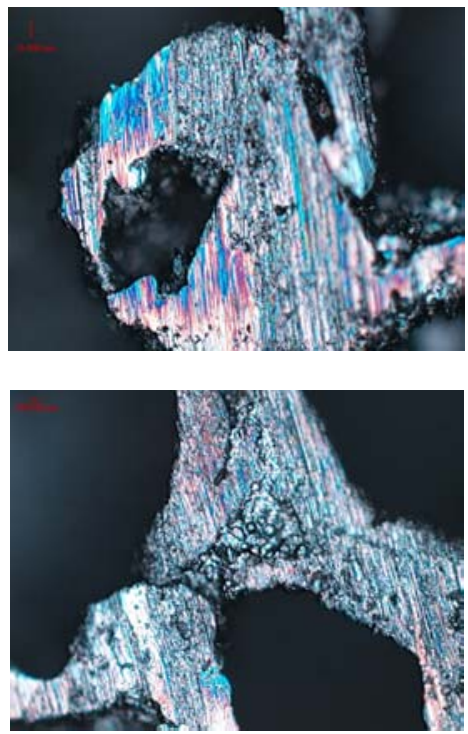

Fig. 4: Microscope image of $\mathrm{Ni}$ after the friction tests. Top: dry friction text 20x; Bottom: lubricated friction test, $20 \mathrm{x}$

materials. The surface of the $\mathrm{Ni}$ changed the total wettability, and the lubricant extended and spread thoroughly on the $\mathrm{Ni}$ surface. Because of the modification of the surface during the cell culture, the surface was well protected. The friction coefficient was smaller after the cell culture and it did not increase during the whole test period. The exposure to cell culture media induced changes to the surface chemistry of Ni. Among those changes, the wettability of $\mathrm{Ni}$ samples changed from hydrophobic to hydrophilic as judged by contact angle. The contact angle of the $\mathrm{Ni}$ sample before cell culture media is $128.3^{\circ}$ which showed that the dry $\mathrm{Ni}$ samples were hydrophobic. After the cell culture media was placed on the $\mathrm{Ni}$ samples. The surface became totally wettable.

The friction coefficients decreased on both BSA solution lubricated $\mathrm{Ni}$ and cell treated media lubricated Ni. This indicated that BSA and culture media performed as lubricants during the friction tests by reducing the interaction of $\mathrm{Ni}$ with the pin. Under the condition similar to a human joint, $\mathrm{Ni}$ samples showed lower friction coefficient during the friction tests, but a high level of toxicity. 


\section{REFERENCES}

1. Chang, L.C., Read, T.A., and Wechsler, M.S. 1953. Reversible single-crystal rocking-curve broadening. Acta Cryst. 6:567.

2. Buehler, W.J. and Wang, F.E. 1968. A summary of recent research on the nitinol alloys and their application in ocean engineering. Ocean Eng. 1:105-120.

3. Heimann, R.B., Schürmann, N., and Müller, R.T. 2004. In vitro and in vivo performance of Ti6A14V implants with plasma-sprayed osteoconductive hydroxylapatite-bioinert titania bond coat "duplex" systems: an experimental study in sheep. J. Materials Science: Materials in Medicine. 15(9):1045-1052.

4. Shi, W., Dong, H., and Bell, T. 2000. Tribological behavior and microscopic wear mechanisms of UHMWPE sliding against thermal oxidationtreated Ti6A14V. Materials Science \& Engineering. A. Structural materials: properties, microstructure and processing. 291(1):27-36.

5. Wang, T. and Dorner-Reisel, A. 2004. Effect of substrate oxidation on improving the quality of hydroxyapatite coating on CoNiCrMo. J. Materials Science. 39(13):4309-4312.

6. Simon, M., Kaplow, R., Salzman, E., and Freiman, D. 1977. A vena cava filter using thermal shape memory alloy. Experimental aspects, Radiology. 125:87-94.

7. Wholey, M.H., Wholey, M., Bergeron, P., Diethrich, E.B., Henry, M., Laborde, J.C., Mathias, K., Myla, S., Roubin, G.S., Shawl, F., Theoron, J.G., Yadav, J.S., Dorros, G., Guimaraens, J., Higashida, R., Kumar, V., Leon, M., Lim, M., Londero, H., Mesa, J., Ramee, S., Rodriguez, A., Rosenfield, K., Teitelbaum, G., and Vozzi, C. 1998. Current global status of carotid artery stent placement. Cathet. Cardiovasc. Diagn. 44:1-6.
8. Acunas, B., Rozanes, I., Akpinar, S., Tunaci, A., Tunaci, M., and Acunas, G. 1996. Palliation of malignant esophageal strictures with selfexpanding nitinol stents: drawbacks and complications. Radiology. 199:648-652.

9. Gottfried, H.W., Gnann, R., Brandle, E., Bachor, R., Gschwend, J.E., and Kleinschmidt, K. 1997. Treatment of high-risk patients with subvesical obstruction from advanced prostatic carcinoma using a thermosensitive mesh stent. Br. J. Urol. 80:623-627.

10. Lu, S.B., Wang, J.F., and Guo, J.F. 1986. Treatment of scoliosis with a shape-memory alloy rod. Chung Hua Wai Ko Tsa Chih. 24:129-132.

11. Castleman, L.S., Motzkin, S.M., Alicandri, F.P., and Bonawit, V.L. 1976. Biocompatibility of nitinol alloy as an implant material. J. Biomed. Mater. Res. 10:695-731.

12. Shi, B., Liang, H., Kuhn, T., and Duffy, L.K. 2006. Surface properties of cell-treated polyethylene terephthalate. Amer. J. Biochem. Biotech. 2:170174.

13. Goyer, R.A. and Clarkson, T.W. 2001. Toxic effects of metals. In: Casarett and Doull's Toxicology, Klaassen, G.D., Editor, pages 811866, McGraw-Hill, N.Y.

14. Costa, M. 1995. Model for the epigenetic mechanism of action on nongenotoxic carcinogins. Am. J. Clin. Nutri. 61:6665-6669. 